Nordic Journal of Modern Language Methodology

2019, 7 (2), 28-53 Peer reviewed Temanummer: Spansk i Norge og det norske i den spansktalende verden.

\title{
CONTACTO CON EL ESPAÑOL EN EL TIEMPO LIBRE EN DIFERENTES CONTEXTOS: ESTUDIANTES DE BACHILLERATO NORUEGOS EN ESPAÑA Y NORUEGA
}

\author{
Berit Grønn' \\ Høgskolen i Østfold, Norge
}

\section{Sammendrag}

I presentasjonen legger jeg fram hovedfunnene fra tre kvalitative intervjuundersøkelser blant spanskelever i vg2 og vg3 i Norge og ved norske skoler i Spania. To av undersøkelsene ble gjennomført i 2016, mens den tredje finner sted skoleåret 2017/18. Hovedtemaer hvordan norske spanskelever eksponeres for og bruker spansk i fritida og på reiser, og hvordan de knytter sine erfaringer med spansk utenom skolen til det de lærer i spansktimene på skolen. Jeg ser spesielt på hvordan elevene eksponeres for spansk i digitale medier og gjennom deltakelse i muntlige og skriftlige kommunikasjonssituasjoner, både online og offline. Målet med undersøkelsene er å avdekke hva elevene foretar seg når de tilfeldigvis blir eksponert for spansk og når de bevisst oppsøker spansk på egen hånd. I intervjuene har elevene fortalt hvordan de går fram for å lytte til, lese, snakke og skrive spansk, delt egne språklæringserfaringer og reflektert over sammenhengen mellom læring på skolen og i fritida. Til slutt skisserer jeg noen muligheter for hvordan et utvalg tekster, som elevene har referert til i intervjuene, kan brukes i undervisningssammenheng, og hva man kan gjøre for å bevisstgjøre elevene på hvordan de kan utnytte egne språklæringserfaringer for å videreutvikle sin språk- og kulturkompetanse.

\footnotetext{
${ }_{1}^{1}$ Berit Grønn es profesora titular de español y didáctica en el Colegio Universitario de Østfold (Noruega). Fue jefa de estudios de lenguas extranjeras y estudios a distancia del Departamento de Economía, Lenguas y Ciencias Sociales del Colegio Universitario de Østfold de 2017 a 2018, y fue asesora de español y latín en el Centro Nacional de Lenguas Extranjeras para la Enseñanza (Fremmedspråksenteret) de 2009 a 2014. Además, fue profesora de español en el Instituto de bachillerato Hellerud (Hellerud vgs, Oslo) de 2006 a 2010.
}

berit.gronn@hiof.no 


\section{Nordic Journal of Modern Language Methodology}

Palabras clave: español lengua extranjera; estudiantes de bachillerato noruegos; aprendizaje informal; contexto extraescolar; herramientas digitales; competencias comunicativas

\section{Introducción}

El presente artículo tiene como tema la adquisición del español como segunda lengua extranjera dentro y fuera de la escuela. Se exponen los resultados principales de dos investigaciones realizadas entre 2015 y 2017, poniendo particular énfasis en lo que hacen los estudiantes de bachillerato noruegos de 17 y 18 años para entrar en contacto con la lengua meta en su tiempo libre, tanto en encuentros físicos como mediante la comunicación digital, y cómo este contacto influye en su proceso de aprendizaje, desarrollo personal y planes para el futuro.

La globalización, la movilidad internacional y los rápidos avances tecnológicos han convertido a la sociedad noruega en una sociedad multicultural, en la que también están presentes la lengua y cultura hispánicas. Al mismo tiempo, hay cada vez más noruegos que realizamos viajes al extranjero o que vivimos cortas o largas temporadas en el extranjero, principalmente en España, pero también en otros países hispanohablantes. Estos fenómenos permiten un mayor y más fácil acceso a la lengua española, tanto en el entorno físico como en el virtual. Además, otro factor que facilita este contacto es la existencia de cinco centros de enseñanza noruegos en España (Fylkesmannen i Oslo og Akershus), todos ellos ubicados en enclaves poblados en su mayoría por europeos no españoles (especialmente escandinavos, ingleses y alemanes), tres en la Comunidad Valenciana, uno en Andalucía y uno en las Islas Canarias.

En este artículo se mostrarán los resultados principales de dos investigaciones. En la primera, que se llevó a cabo en 2015-2016 (Christiansen y Grønn 2017) participaron un total de 205 informantes, todos residentes en Noruega. En la segunda, que se llevó a cabo en 2016-2017, participaron 17 informantes, todos residentes en España. En ambos estudios el objetivo es investigar cómo proceden los estudiantes de español para practicar la lengua meta en su vida diaria y tiempo 
Temanummer: Spansk i Norge og det norske i den spansktalende verden.

libre. El propósito es descubrir en qué contextos y con qué fines usan el español. En el estudio de 2016-2017 interesaba, además, profundizar en cómo estos estudiantes perciben su vida en España.

En la Educación General noruega orientada a la universidad, la asignatura de las segundas lenguas extranjeras es obligatoria durante los dos primeros cursos del bachillerato y es optativa de profundización el tercer, y último, curso. El enfoque del plan de estudios de lenguas extranjeras (Utdanningsdirektoratet 2006) corresponde con el enfoque del Marco Cómun Europeo de Referencia para las lenguas (MCER) (Instituto Cervantes 2002), ya que adopta un enfoque práctico y activo (Skjær 4). El objetivo es que el estudiante se convierta en usuario de la lengua meta, por lo que se enfatiza el desarrollo de las destrezas comunicativas (producción oral y interacción oral espontánea, comprensión auditiva y comprensión lectora, producción escrita). En consecuencia, en el aula de ELE se fomentan las tareas comunicativas y el uso de textos auténticos. Dada la importancia que se le concede a la competencia comunicativa, en esta investigación se quiso averiguar cómo y de qué forma los estudiantes ponen dicha competencia en práctica en ámbitos extraescolares. Para ello, se quiso dar respuesta a las siguientes preguntas de investigación: 1) ¿qué posibilidades tienen los estudiantes para practicar el español y cómo las aprovechan?, 2) ¿en qué contextos y con qué propósitos usan el español y cuáles son las características de este uso?, 3) ¿hacen uso los estudiantes de las nuevas tecnologías para acceder a una comunicación en español, y en tal caso, en qué consiste esta comunicación digital?

Con la emergencia de nuevos espacios de aprendizaje informal, para poder ofrecer una enseñanza que fomente el aprendizaje formativo y el crecimiento personal, es indispensable tener buenos conocimientos del perfil del estudiante de hoy. Hasta ahora no se han realizado estudios enfocados en el uso del español de estudiantes del bachillerato noruegos en los distintos ambientes extraescolares y, a excepción del trabajo realizado por Vartdal (2007), son pocos los trabajos centrados en la vida diaria de jóvenes noruegos residentes en España.

Por ello, la presente investigación pretende contribuir a incrementar nuestro conocimiento sobre cómo las experiencias personales de los estudiantes con la 


\section{Nordic Journal of Modern Language Methodology}

2019, 7 (2), 28-53 Peer reviewed

Temanummer: Spansk i Norge og det norske i den spansktalende verden.

lengua meta fuera del contexto escolar influyen en el proceso de aprendizaje. De este modo, los resultados de la investigación pueden servir de inspiración en el diseño de actividades didácticas que resulten significativas para el estudiante.

En los siguientes apartados se mostrará en primer lugar las características del sistema educativo noruego y del plan de estudio de segundas lenguas extranjeras. Posteriormente se hará un resumen del marco teórico y los métodos de investigación empleados. Los resultados se analizarán a la luz de las teorías socioculturales sobre el aprendizaje de segundas lenguas extranjeras (Lantolf yThorne 2006; 2011; Swain, Kinnear, y Steinman 2010) y los cuatro ámbitos principales en los que puede tener lugar el aprendizaje de las lenguas, presentados en el MCER. Me centraré especialmente en los resultados del estudio de 2016-2017, los cuales analizaré de forma comparativa con algunos resultados destacados de la parte cualitativa del estudio de 2015-2016.

\section{El sistema educativo noruego y su plan de estudios de lenguas extranjeras}

En el sistema educativo noruego, la educación primaria y la educación secundaria obligatoria (grunnskolen) constituyen diez cursos de enseñanza básica obligatoria. Después, los estudiantes tienen la posibilidad de seguir sus estudios en el Bachillerato o la Formación Profesional (videregående opplæring), que consisten de tres cursos. Los idiomas oficiales de Noruega son el noruego, idioma mayoritario, y el sami, idioma minoritario. De acuerdo a la reforma escolar noruega LK06 (Kunnskapsdepartementet), que entró en vigor en 2006, los alumnos empiezan a estudiar noruego e inglés en el primer curso, a la edad de seis años. El plan curricular LK06, común para todos los alumnos hasta los 18 años, no considera el inglés como segunda lengua extranjera. Desde una perspectiva lingüística, el inglés no es la lengua materna de la gran mayoría de los alumnos, pero tradicionalmente la sociedad noruega mantiene estrecho contacto con el mundo anglosajón. Los noruegos estamos expuestos al inglés constantemente a través de los medios de comunicación, los medios digitales, viajes y estancias en países anglosajones, etc. 


\section{Nordic Journal of Modern Language Methodology}

2019, 7 (2), 28-53 Peer reviewed Temanummer: Spansk i Norge og det norske i den spansktalende verden.

Según LK06, los centros de enseñanza de primaria pueden ofrecer segundas lenguas extranjeras, como el alemán, francés, español o chino, si lo desean (Utdannings- og forskningsdepartementet 48), pero pocas escuelas en Noruega optan por ello. Los centros de enseñanza noruegos situados en España suelen ofrecer clases de español una o dos horas semanales en primaria. Debido a que no es asignatura obligatoria en este ciclo, los alumnos que reciben clases de español en primaria no siguen un plan de estudios propio de segundas lenguas extranjeras.

La Educación Secundaria Obligatoria comprende los cursos $8^{0}, 9^{0}$ y $10^{\circ}$, en los que los alumnos tienen de 13 a 15 años de edad. En el $8^{\circ}$ curso, los estudiantes tienen que elegir entre una segunda lengua extranjera, estudios suplementarios de idioma (inglés, noruego o sami), matemáticas o preparación para el mundo laboral. El Bachillerato (Videregående $=$ Vg) consta de tres cursos, Vg1, Vg2 y Vg3, de los 16 a 18 años. En la Educación General orientada hacia la universidad las segundas lenguas extranjeras es una asignatura común (obligatoria) en los cursos Vg1 y Vg2. Además, se puede estudiar una segunda lengua extranjera como asignatura optativa de profundización en $\mathrm{Vg} 1, \mathrm{Vg} 2$ y/o Vg3.

El plan de estudios noruego de lenguas extranjeras es común para todas las lenguas y está organizado en tres niveles (Utdanningsdirektoratet 2006). El nivel I se da en grunnskolen (la "ESO") durante los cursos $8^{0}, 9^{0}$ y $10^{\circ}$. En los Estudios Generales del bachillerato es obligatorio estudiar una segunda lengua extranjera en los niveles I o II durante los dos primeros cursos. Un estudiante que ha cursado el nivel I en grunnskolen (la "ESO") puede seguir con la misma lengua en el nivel II en el bachillerato y, además, puede elegir otra segunda lengua extranjera en el nivel I. Si el estudiante no escoge una segunda lengua extranjera en grunnskolen (la "ESO"), sino que opta por una de las otras alternativas, como Estudio Suplementario de inglés o Preparación para el mundo laboral, tiene que estudiar una segunda lengua extranjera en los niveles I+II durante los tres cursos, Vg1, Vg2 y Vg3. Las opciones que tienen los estudiantes quedan ilustradas en la siguiente Figura 1. 
Nordic Journal of Modern Language Methodology

2019, 7 (2), 28-53 Peer reviewed

Temanummer: Spansk i Norge og det norske i den spansktalende verden.

\begin{tabular}{|l|l|l|}
\hline \multicolumn{2}{|c|}{ Asignatura común (obligatoria) Segundas lenguas extranjeras } \\
\hline Nivel I & Nivel II & Nivel I+II \\
\hline En $8^{0}, 9^{0}$ y $10^{\circ}$ (la "ESO") & Vg1, Vg2 & Vg1, Vg2, Vg3 (Bachillerato) \\
0 & (Bachillerato) & \\
Vg1, Vg2 (Bachillerato) & & \\
\hline
\end{tabular}

\begin{tabular}{|l|l|l|}
\hline \multicolumn{3}{|l|}{ Asignatura optativa de profundización Segundas lenguas extranjeras } \\
\hline Nivel I & Nivel II & Nivel III \\
\hline Se puede escoger en Vg1 & Se puede escoger en Vg2 & $\begin{array}{l}\text { Se puede escoger en Vg3 } \\
\text { (Bachillerato) }\end{array}$ \\
\hline (Bachillerato) & (Bachillerato) & (Bato \\
\hline
\end{tabular}

Desde 2006 hasta la actualidad, el español es la lengua más elegida por los alumnos, seguida por el alemán y el francés. En la "ESO" noruega unos $75 \%$ de los alumnos estudian una segunda lengua extranjera (Fremmedspråksenteret 2015), o sea, la mayoría de los estudiantes empiezan con una segunda lengua extranjera a los 13 años. En el bachillerato, con un promedio de 60000 estudiantes al año, el español es la segunda lengua extranjera más solicitada, seguida del alemán y del francés (Utdanningsdirektoratet 2015; Fremmedspråksenteret 2018). La mayor parte de los estudiantes que escogen español nivel I en grunnskolen (la "ESO") continúan con el español nivel II en el bachillerato. En 2016/2017, 648 alumnos estudiaron el español nivel III. Este número no es muy alto comparado con otras asignaturas de profundización optativas, pero es mayor que el alemán y el francés nivel III (Fremmedspråksenteret 2018). El número de estudiantes que escogen una segunda lengua extranjera como asignatura de profundización en $\mathrm{Vg} 1$ y Vg2 es aún más bajo.

\section{Marco teórico}

Me he basado en las teorías que analizan la adquisición de segundas lenguas extranjeras (L2) desde una perspectiva sociocultural. Tomando como punto de partida la teoría educativa de Vygotsky, el concepto de aprendizaje situado, uno de los conceptos fundamentales vygotskyanos, enfatiza la relevancia del contexto sociocultural en el que tiene lugar el proceso de aprendizaje, puesto que las actividades humanas no se pueden entender aisladas del ambiente social en en que tienen lugar (Säljö 2016: 248). Además, Vygotsky consideraba la actividad humana como una actividad mediada, que comporta siempre el uso de algún tipo de 
Temanummer: Spansk i Norge og det norske i den spansktalende verden.

herramienta o artefacto. Respecto a los procesos psicológicos complejos, Vygotsky distinguía entre las herramientas simbólicas (signos) y las herramientas físicas (recursos materiales), siendo el lenguaje la herramienta simbólica principal (Kozulin xxxix).

En términos de Vygotsky, los procesos mentales superiores aparecen dos veces, primero a nivel social (interpsicológico), durante las actividades compartidas, y, luego, a nivel individual (intrapsicológico), cuando el individuo ha interiorizado el aprendizaje que ha tenido lugar durante las actividades compartidas (Vygotsky 1978: 58). Los estudios de Vygotsky se centran principalmente en cómo los niños se desarrollan pensamientos cada vez más complejos. Sus estudios muestran cómo los niños, a través de sus experiencias personales y en interacción con otros, adquieren conocimientos y destrezas de forma espontánea e irreflexiva, mientras que en la instrucción escolar, haciendo uso de herramientas de mediación, alcanzan un aprendizaje más estructurado y reflexivo. No obstante, tanto el desarrollo de la actividad espontánea como la de la no espontánea se interrelacionan y se influyen mutuamente (Vygotsky 2012: 202-203).

Al aplicar las teorías de Vygotsky a la investigación de la adquisición de L2, Lantolf y Thorne subrayan que el aprendiz, cuando entra en contacto con la lengua meta y la practica en interacciones verbales, dentro o fuera del aula, presta atención a cómo sus interlocutores emiten y reciben los enunciados, se fija en el contenido y en cómo están construidos los enunciados, reconoce palabras, expresiones, estructuras gramaticales y formas de expesarse que ya ha aprendido y, al mismo tiempo, capta otras nuevas. De esta manera, va captando el uso de modelos del idioma, y los interioriza, a nivel intrapsicológico. Es decir, no se trata de una mera imitación de los modelos de idioma, sino una transformación y reelaboración (Lantolf y Thorne 2011: 207). Por lo tanto, para alcanzar un mayor dominio de la lengua meta, el aprendiz debe usarla de diferentes maneras, en diferentes tipos de actos de comunicación y en diferentes contextos (Tornberg 76).

Además, el rápido avance de las nuevas tecnologías aumenta las posibilidades y la flexibilidad para acceder a nuevos ambientes de aprendizaje. Gracias a las herramientas digitales las posibilidades del aprendiz de L2 para 


\section{Nordic Journal of Modern Language Methodology}

Temanummer: Spansk i Norge og det norske i den spansktalende verden.

practicar la lengua meta aumenta, tanto en el contexto escolar como en su tiempo libre. No obstante, no es suficiente tener las herramientas a su disposición, el aprendiz tiene que hacer uso de ellas, si no, no hay proceso de mediación (Swain, Kinnear, y Steinman 2). Lo mismo sucede en el mundo físico, si el aprendiz no aprovecha las oportunidades de interacción que se le presentan, por ejemplo, para participar en una interacción oral espontánea en español, la actividad de mediación con la lengua meta no se produce.

Para el análisis de los datos recopilados también me he basado en el MCER. Se distingue entre cuatro ámbitos principales (esferas de acción y áreas de interés), donde se realizan el aprendizaje y la enseñanza de las lenguas: el personal, el público, el profesional y el educativo (Instituto Cervantes 49). El ámbito personal abarca la vida privada del individuo, su familia, amigos, sus aficiones, etc. En el ámbito público la persona actúa como miembro de la sociedad o de alguna organización. En el ámbito educativo la persona participa en un aprendizaje formal y en el ámbito profesional, la persona ejecuta su trabajo o su profesión. La capacidad del aprendiz de poner en acción su competencia comunicativa en L2 depende en gran medida de las condiciones físicas en la que tiene lugar la comunicación y de la capacidad del estudiante de actuar en un momento dado (Instituto Cervantes 51).

\section{Metodología}

Se presentan los resultados de dos estudios. En el primer estudio de 2015-2016 (Christiansen y Grønn, 2017) participaron 205 informantes y se emplearon métodos cuantitativos y cualitativos, mientras que en el estudio de 2016-2017, participaron solo 17 informantes y se utilizó exclusivamente la entrevista cualitativa como método de investigación. Los estudiantes que participaron en el estudio de 2015-2016 residían en Noruega, mientras que los que participaron en el de 2016-2017, residían en España. No obstante, los participantes de ambos estudios compartían una serie de rasgos: eran todos de la misma edad, entre 17 y 18 años, y recibían la formación postobligatoria videregående opplæring (Bachillerato) dentro del sistema educativo noruego. Es decir, la lengua principal dentro de su ámbito escolar era el noruego y 


\section{Nordic Journal of Modern Language Methodology}

Temanummer: Spansk i Norge og det norske i den spansktalende verden.

los lazos de los estudiantes con la lengua y la cultura noruegas, si bien de variable intensidad, eran fuertes. El estudio de 2015-2016, se dividía en dos partes: primero se realizó una encuesta en línea con preguntas relativas a las oportunidades que tenían los estudiantes para practicar el español en su vida diaria, tiempo libre y en los viajes de ocio. 181 estudiantes de español del nivel III participaron. Posteriormente, a partir de los resultados de la encuesta, se realizó entrevista semiestructurada con diez preguntas abiertas.

El objetivo era explorar más detenidamente algunos de los temas que habían surgido en la encuesta. En las entrevistas participaron 24 estudiantes de español del nivel III y se realizaron en noruego en los centros de enseñanza de los respectivos informantes. Los informantes fueron entrevistados en pequeños grupos de 2 a 4 estudiantes con el fin de que los informantes compartieran sus experiencias y reflexiones (Kreuger, Casey 177-178). Se presentan a continuación las preguntas del guión (traducción propia):

1) ¿Cuáles eran tus motivos para elegir el español nivel III?

2) ¿Cuándo, en qué situaciones y con qué propósito practicas el español fuera de la escuela?

3) ¿En qué situaciones practicas español cuando estás de viaje?

4) En tu tiempo libre, ¿practicas el español en espacios digitales? ¿A qué sitios web en español accedes? ¿Con qué frecuencia y con qué fines?

5) ¿Qué planes tienes para el futuro?

Las respuestas de estas entrevistas se clasificaron en tres categorías: 1) Los motivos para la elección del español nivel III, 2) El uso del español en la vida diaria y el tiempo libre, y 3) Planes para el futuro. La segunda categoría se dividió a su vez en tres subgrupos: a) destrezas receptoras (auditivas y lectoras), b) destrezas productivas (orales y escritas) y c) uso de herramientas digitales.

El estudio de 2016-2017 se realizó únicamente con 17 participantes y se llevó a cabo en dos centros escolares noruegos en España en los que se ofrece tanto grunnskolen (enseñanza básica) como los tres cursos de videregående skole 


\section{Nordic Journal of Modern Language Methodology}

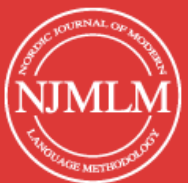

2019, 7 (2), 28-53 Peer reviewed Temanummer: Spansk i Norge og det norske i den spansktalende verden.

(enseñanza postobligatoria). Se utilizó la entrevista cualitativa semiestructurada individual para la recolección de los datos con el objetivo de dejar espacio a los informantes para hablar libremente y verbalizar sus reflexiones sobre la adquisición del español mediante ejemplos concretos y pequeñas narraciones de su propia vida (Benson y Nunan 18-19; Kvale y Brinkmann 122). Las preguntas del guión de la entrevista eran similares a las de la parte cualitativa del estudio de 2015-2016, con la excepción de la primera pregunta, que fue diseñada específicamente para los estudiantes que cursaban el nivel III en Noruega. Se añadieron dos preguntas adaptadas al contexto en que se encontraban los informantes (comunidad noruega en España). Otro rasgo diferenciador era la selección de los informantes y el nivel que estudiaban de acuerdo con el plan de estudios noruego de lenguas extranjeras. Los informantes de 2015-2016 eran todos estudiantes del nivel III en Vg3, mientras que los del 2016-2017 cursaban Vg2 y Vg3, los cuales se dispersaban por los niveles I, II, I+II o III. Siguen a continuación las seis preguntas del guión de la entrevista (traducción propia):

1) ¿Qué curso sigues ahora, vg2 o vg3? Qué nivel de español estás estudiando/has estudiado?

2) ¿Dónde has aprendido español, en España, en Noruega u en otro país?

3) ¿Cuándo, en qué situaciones y con qué propósito practicas el español fuera de la escuela?

4) En tu tiempo libre, ¿practicas el español en espacios digitales? ¿A qué sitios web en español accedes? ¿Con qué frecuencia y con qué fines?

5) ¿Qué planes tienes para el futuro?

6) ¿Cómo es vivir en España? En tu opinión, ¿cuáles son las ventajas y los inconvenientes?

Las entrevistas se realizaron en noruego y tuvieron lugar en los centros de los estudiantes. En el análisis de los datos recogidos se siguió el mismo procedimiento que en la parte cualitativa de la investigación de 2015-2016 con la diferencia de que en la primera parte se clasificaron los diferentes niveles que estaban estudiando o que habían estudiado los informantes (niveles I, II, I+II o III). Para mantener el anonimato de los 


\section{Nordic Journal of Modern Language Methodology}

2019, 7 (2), 28-53 Peer reviewed

Temanummer: Spansk i Norge og det norske i den spansktalende verden.

informantes se ocultaron los nombres de los centros de enseñanza y los verdaderos nombres de los informantes en ambos estudios fueron sustituidos por pseudónimos.

\section{Resultados y análisis I}

\section{Las entrevistas cualitativas (2015-2016) Motivos de elección de la asignatura de profundidad español nivel III}

Según los informantes, las razones principales por las que escogieron español nivel III en Vg3 fue el deseo de seguir desarrollando sus destrezas comunicativas, sobre todo las orales, y seguir aumentando su competencia cultural. En Vg2, la mayoría de los informantes realizaron un viaje de estudios a España de una semana de duración organizado por sus respectivos centros de enseñanza. Según los informantes, ese viaje fue una experiencia muy positiva, ya que pudieron practicar el español en un ambiente auténtico, y eso, indudablemente, influyó en la toma de su decisión.

\section{El contacto con el español en la vida diaria/el tiempo libre: encuentros físicos}

Durante las entrevistas los informantes dieron muchos ejemplos de contextos y situaciones en los que practican el español en interacciones cara a cara, tanto en Noruega como en el extranjero, sobre todo en viajes de ocio a países hispanohablantes, pero también a otros países como Holanda, Inglaterra, Suiza y Brasil. Destacaron las experiencias positivas describiendo actos de comunicación dialógicos en los que habían participado y se habían desenvuelto con éxito en español. Sirve de ejemplo la siguiente historia facilitada por una de las informantes:

Estando en un restaurante en Amsterdam, entablé conversación con una familia chilena, que estaba sentada en la mesa de al lado. Les impresionó que yo hablara español y les interesaba mucho saber sobre Noruega.

Bastantes informantes viajan regularmente a España en época de vacaciones, dado que su familia o conocidos de la familia poseen un apartamento o una casa de verano allí. Entonces practican el español en tiendas, bares y restaurantes, etc. 
Temanummer: Spansk i Norge og det norske i den spansktalende verden.

Varios de los entrevistados tienen amigos y conocidos hispanohablantes, en Noruega y/o en el extranjero. Normalmente se comunican con ellos en noruego o inglés, pero todos afirman que desarrollan competencias auditivas cuando los oyen hablar en español. Así, un estudiante indica:

Uno de mis mejores amigos es medio noruego, medio venezolano. Cuando estamos en su casa y su padre nos habla en español, siempre intento captar lo que dice.

Algunos tienen familiares hispanohablantes con los que se comunican en español. Dos utilizan de vez en cuando el español en el ámbito profesional, la primera tiene trabajo parcial en una tienda y la otra en un gimnasio, donde hay clientes/socios hispanohablantes, entre otras nacionalidades. Un tercio de los entrevistados, tienen pocas posibilidades de practicar la expresión oral en su tiempo libre: ni conocen a nadie de habla española ni realizan viajes a España o a otro país hispanohablante.

\section{El contacto con el español en la vida diaria/el tiempo libre: espacios digitales}

Todos los informantes disponen de herramientas digitales en su hogar, lo cual les permite un fácil acceso a páginas web, redes sociales y servicios de streaming. Generalmente escuchan música, ven películas y series de televisión en inglés. Usan también los servicios de streaming para escuchar música de artistas hispanos. A veces se esfuerzan para entender las letras de las canciones, otras veces las escuchan simplemente para relajarse o bailar. Subrayan que las similitudes entre palabras, expresiones y algunas estructuras gramaticales del inglés y el español facilita la comprensión auditiva.

Un tercio de los estudiantes entrevistados confirman que hacen un esfuerzo consciente por acceder al español en medios digitales, entre otras cosas, para compensar la ausencia total o parcial del español en su entorno físico inmediato. Su uso del español en los medios digitales se caracteriza por estar muy vinculados a sus áreas de interés: los que están interesados en la moda, siguen blogs o videoblogs de moda, los que están interesados en deporte, leen revistas digitales de 


\section{Nordic Journal of Modern Language Methodology}

Temanummer: Spansk i Norge og det norske i den spansktalende verden.

deporte como Marca y El as. Además, destacan que, para estar al tanto de las últimas tendencias de moda o de las últimas noticias de actualidad del mundo del deporte, es una gran ventaja saber español. Sin embargo, el objetivo de usar estos espacios digitales, no es solamente entretenerse o disponer de información actualizada respecto a sus hobbies e intereses, sino también mejorar sus habilidades comunicativas en español, sobre todo la comprensión auditiva y lectora:

La gran ventaja de los videoblogs, es que se puede ver las mismas secuencias varias veces, los españoles hablan muy de prisa y tengo que concentrarme para captar todo lo que dicen, afirma una de las informantes.

O sea, el aprendizaje informal, aunque se caracterizan por producirse de manera fortuita e incidental, puede también realizarse de forma estructurada y con una intencionalidad por parte del aprendiz. La tecnología digital les facilita una serie de herramientas para entrar en contacto con la lengua meta, no solo en el ámbito educativo, sino también personal, lo que les permite controlar su propio aprendizaje $y$, de este modo, las fronteras entre el aprendizaje formal e informal se van difuminando (Lantolf y Thorne 2006: 67-68).

\section{Planes para el futuro}

Los factores externos que inciden en el aprendizaje de la lengua meta están íntimamente relacionados con el contexto mental y las metas que cada uno se propone a corto y largo plazo (Lantolf y Thorne 2011: 218). En cuanto al español, las metas que se proponen los entrevistados, tanto a corto como a largo plazo, son principalmente desarrollar sus habilidades lingüísticas a nivel oral coloquial. Todos tienen como objetivo estudiar una carrera universitaria, aunque algunos barajan la opción de tomarse un año libre para trabajar o viajar antes de iniciar sus estudios universitarios. Ninguno ha considerado estudiar filología española o traducción e interpretación, aunque tres de ellos tampoco lo descartan. La mayoría se propone estudiar carreras de economía y empresa, medicina, odontología o derecho, etc. No obstante, todos están convencidos de que harán uso de sus competencias comunicativas en español en el futuro, en el ámbito personal, público, educativo y/o 


\section{Nordic Journal of Modern Language Methodology}

Temanummer: Spansk i Norge og det norske i den spansktalende verden.

profesional. Varios ya tienen planeada una estancia Erasmus en España y explican detalladamente qué carreras y qué universidades noruegas ofrecen estas estancias. Un par de los entrevistados también ha averiguado las posibilidades de pasar un año de intercambio en algún país latinoamericano o en estados norteamericanos como California y Nueva York. Todos son muy conscientes de que el español es una de las lenguas más habladas del mundo y, por consiguiente, creen que sus conocimientos de español serán muy útiles a la hora de establecer contactos, tanto en el mundo académico y profesional, como en el ámbito de ocio.

A pesar de esto, es sorprendente que solo cinco de los participantes señalan la importancia de adquirir una competencia comunicativa en un código asociado a un registro más formal y académico. Solamente cuatro de los estudiantes entrevistados han intentado leer novelas en español sin que sea trabajo escolar.

\section{Resultados y análisis II}

\section{Las entrevistas cualitativas (2016-2017)}

\section{La asignatura de español: los niveles I, II, I+II o III}

En el momento de realizarse las entrevistas, seis de los informantes residentes en España cursaban el segundo año del bachillerato, Vg2, y doce el tercero, Vg3. En cuanto al nivel de español alcanzado por los informantes, según el plan de estudios de lenguas extranjeras, había gran variedad: Entre los doce de Vg3, una estudiante había

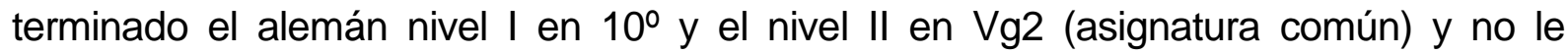
interesaba aprender español. Dos estudiaban el español nivel III como asignatura de profundización optativa. Seís habían terminado con el español nivel II en Vg2 (asignatura común) y habían optado por otras asignaturas de profundización optativa en Vg3, como Marketing y Psicología. Una había terminado alemán nivel I en la "ESO" noruega y español nivel I en Vg2 (asignatura común). Dos habían terminado Profundización de inglés en la "ESO" noruega y estudiaban español nivel |+|l (asignatura común). Entre los cinco estudiantes de Vg2, cuatro estudiaban español nivel II y la quinta el nivel I+II (asignatura común). Los resultados se presentan en la siguiente Figura 2. 
Nordic Journal of Modern Language Methodology

2019, 7 (2), 28-53 Peer reviewed Temanummer: Spansk i Norge og det norske i den spansktalende verden.

\begin{tabular}{|l|l|l|l|}
\hline \multicolumn{4}{|l|}{ Español como segunda lengua extranjera: informantes de Vg3 } \\
\hline Asignatura común & $\begin{array}{l}\text { Nivel II } \\
\text { (terminado }\end{array}$ & $\begin{array}{l}\text { Nivel I+II } \\
(2016 / 17)\end{array}$ & $\begin{array}{l}\text { Nivel III } \\
(2016 / 17)\end{array}$ \\
\hline $\left.\begin{array}{l}\text { Nivel I } \\
\text { (terminado }\end{array} 2015 / 16\right)$ & $2015 / 16)$ & & \\
\hline 1 & 6 & 2 & 2 \\
\hline
\end{tabular}

\begin{tabular}{|l|l|}
\hline \multicolumn{2}{|l|}{ Español como segunda lengua extranjera (asignatura común): informantes de Vg2 } \\
\hline Nivel II & Nivel I+II \\
\hline 4 & 1 \\
\hline
\end{tabular}

Es decir, algunos de ellos llevaban muchos años aprendiendo español, mientras que otros solamente uno o dos. Además, cinco de los informantes residían en España desde la infancia, entre los cuales una tenía madre hispanohablante y había cursado primaria en un centro escolar español. Los cuatro restantes habían recibido clases de español como segunda lengua extranjera en los cursos anteriores al 8․․

\section{El contacto con el español en la vida diaria y el tiempo libre: entorno físico inmediato}

En los contextos extraescolares, los informantes están expuestos al noruego y al inglés, y, en menor medida, al español. Todos hablan noruego en casa, con la excepción de la informante que tiene madre hispanohablante y todos tienen amigos noruegos, la gran mayoría de ellos compañeros de clase. Además, los informantes afirman que en su vida diaria escuchan gente hablando en español en su entorno físico inmediato, por la calle, en tiendas, en bares y restaurantes, etc. No obstante, como se encuentran en una zona en la que residen personas de muchas nacionalidades diferentes, la lengua que más usan en el ámbito público es el inglés. Por eso, en su vida diaria, alternan constantemente entre el noruego, el inglés y (en menor medida) el español. De hecho, varios de los informantes subrayan que se consideran miembros, no solamente de la comunidad noruega, sino también de una comunidad multicultural, y que, desde que viven en España, su competencia oral en inglés ha mejorado notablemente. Trece de los informantes confirman que intentan hablar español fuera del ámbito escolar, pero varía mucho con qué frecuencia y en 
Nordic Journal of Modern Language Methodology

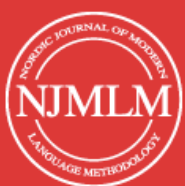

2019, 7 (2), 28-53 Peer reviewed Temanummer: Spansk i Norge og det norske i den spansktalende verden.

qué contextos. De estos trece, cinco tienen amigos españoles con los cuales se comunican en español o combinando el inglés y el español. Estos estudiantes señalan:

Vivo aquí desde hace quince años, y tengo muchos amigos tanto noruegos como españoles. Fui a un jardín infantil español. Luego, entré en primaria en la escuela noruega. Mis amigos españoles viven en el barrio, y nos encontramos de vez en cuando, salimos juntos, etc. Creo que soy bilingüe, no me cuesta nada pasar del noruego al español, y del español al noruego.

Vivo en España desde pequeña. Mi casa está en otra ciudad, mis amigos españoles viven allí. A veces salgo con ellos, a veces con mis amigos noruegos. Como hablo español en casa, necesito practicar el noruego con mis amigos noruegos. A veces los ayudo con las tareas de español.

Tengo una pandilla de amigos de muchas nacionalidades, también españoles. Nos comunicamos en español y creo que domino el español coloquial bastante bien.

Casi todos mis amigos son de habla inglesa, pero tengo una amiga española, $y$ a través de ella he conocido a sus amigas. Normalmente nos comunicamos en inglés, pero si no me entienden, intento expresar lo mismo en español.

Yo llegué a España el año pasado y sabía poco español. Este año he conocido a jóvenes españoles. A veces salgo con ellos, vamos a bares y cafeterías. Tengo la impresión de que los españoles salen mucho. Para entendernos alternamos entre el inglés y el español.

Estos cinco informantes subrayan que en el grupo de amigos con los que interaccionan, las relaciones interpersonales se caracterizan por la simpatía y colaboración, lo cual favorece el aprendizaje del español. Impulsados por los estímulos verbales que les llegan de sus amigos, aprenden sobre todo un lenguaje coloquial y la jerga juvenil.

Los ocho informantes restantes no tienen amigos españoles, pero intentan hablar español en tiendas, en cafeterías, bares y restaurantes y, a veces, en la playa si conocen a jóvenes españoles allí o si salen con amigos noruegos por la noche. En palabras de los propios estudiantes:

No hablo mucho español en mi tiempo libre, pero a veces intento hablar español en las tiendas. Intento construir frases cortas y utilizo palabras sueltas 


\section{Nordic Journal of Modern Language Methodology}

Temanummer: Spansk i Norge og det norske i den spansktalende verden.

y el lenguaje corporal señalando qué productos o qué prenda de ropa me gustaría comprar.

Cuando voy de tiendas o salgo con mis amigos noruegos intento hablar español. Si los dependientes o los camareros no nos entienden, pasamos al inglés. Siempre intentamos en español primero.

Tres de los informantes han practicado o todavía practican algún deporte organizado por federaciones españolas locales y opinan que esto les favorece a la hora de expresarse en español:

En primaria entrenaba al fútbol y el entrenador nos hablaba siempre en español. También he practicado boxeo, uno de mis entrenadores era argentino, el otro noruego. Yo no tengo amigos españoles, pero como llevo muchos años viviendo aquí, creo que me defiendo bien en español.

El deporte y el ejercicio físico no organizados también brindan oportunidades para practicar el español:

Por las tardes solemos jugar al voleibol en la playa. De vez en cuando jugamos contra jóvenes españoles, que también suelen estar en la playa. Entonces hablamos español.

De esta manera, las actividades deportivas organizadas y no organizadas constituyen un puente entre los jóvenes de la comunidad noruega y la española. Además, dos de los informantes han obtenido el carné de conducir en España y, aunque se comunicaban con los profesores de la escuela de tráfíco en inglés, hablaban cada vez más español con ellos. Cuatro de los informantes no tienen amigos ni conocidos españoles y tampoco practica el español en tiendas, etc., pero se esfuerzan por entender qué dicen otras personas que hablan español:

Comprendo bastante si escucho a alguien hablando en español, pero yo no hablo nunca español fuera de la escuela.

\section{El contacto con el español en la vida diaria y el tiempo libre: espacios digitales}

En los espacios digitales los informantes utilizan sobre todo el noruego y el inglés. Prefieren acceder a páginas web en inglés, ver series televisivas y películas en 


\section{Nordic Journal of Modern Language Methodology}

Temanummer: Spansk i Norge og det norske i den spansktalende verden.

inglés en Netflix, Viaplay, etc. Sus blogs y videoblogs favoritos están en inglés o noruego. Varios de ellos indican que echan de menos a familiares, amigos y compañeros de clase en Noruega y utilizan las redes sociales principalmente para mantenerse en contacto con ellos. Cinco acceden a los medios digitales para practicar el español. Cuatro destacan que a veces ponen subtítulos en español cuando ven películas y series norteamericanas en plataformas digitales, y dos de ellos van al cine si ponen una película en inglés con subtítulos en español. La mayoría de los informantes no ven casi nunca programas, películas o series de televisión doblados al español, aunque hay un par de excepciones: una de los informantes vio la serie española Velvet, y los cinco que llevan muchos años en España ven programas o series de televisión españoles de vez en cuando. Los cinco informantes que tienen amigos españoles se comunican con ellos mediante servicios de mensajería como Whatsapp, por ejemplo, para quedar. Casi todos afirman que escuchan música hispana, aunque la lengua predominante en este terreno también es el inglés. Seis de los informantes no escuchan nunca música en español. Otros, por el contrario, descargan música de iTunes, Spotify etc. tanto en inglés y noruego como en español, sobre todo estrellas de éxito internacional que cantan tanto en inglés como en español, como Enrique Iglesias, Jennifer López, Ricky Martín y Pitbull. También escuchan artistas latinoamericanos como Sebastián Yatra y Luis Fonsi. Tratándose de la música hispana, los estilos de música predilectos son el pop latino y el reggaetón. Pero hay excepciones:

Como mi madre sabe español, desde pequeña escucho música española de distintos géneros.

Yo, a veces, voy a conciertos de artistas españoles. Si vienen aquí para dar conciertos, voy a verlos.

Estos resultados ponen de manifiesto el valor de la música como herramienta entrar en contacto con la lengua española y la cultura hispana. 
Nordic Journal of Modern Language Methodology

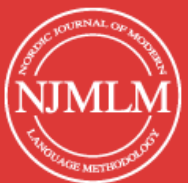

2019, 7 (2), 28-53 Peer reviewed Temanummer: Spansk i Norge og det norske i den spansktalende verden.

\section{Reflexiones sobre la vida en España: factores que favorecen o impiden el uso del español}

Los informantes destacan como positivo que, aunque no aprovechan siempre las oportunidades para practicar el español, al menos están más expuestos al español que en Noruega. Todos subrayan que, viviendo en un ambiente internacional, llegan a conocer otras lenguas y culturas, no solo la española. En su opinión, el hecho de estar expuestos a otras lenguas y culturas hace que sean más abiertos y tolerantes hacia la diversidad cultural y lingüística. A pesar de ello, algunos opinan y lamentan que la comunidad noruega tiende a aislarse, que el lugar donde viven es como un gueto. Algunos piensan que es difícil entablar amistades con jóvenes españoles, mientras que otros no. Los cinco que han llegado a hacer amistades, lo han hecho por tres vias: 1) a través del contacto con vecinos españoles, 2) a través de amigos de nacionalidad no española también residentes en España, o 3) participando en actividades de deporte y de ocio. Sólo dos de los informantes residen en barrios formados mayoritariamente por españoles. Los demás residen en urbanizaciones pobladas por noruegos y/u otras nacionalidades europeas no españolas, y, por consiguiente, se comunican con sus vecinos en noruego o inglés. Para algunos también hay barreras mentales que les impiden entrar en contacto con españoles. Una de los informantes afirma lo siguiente:

Vivimos en un lugar que está lleno de turistas. Tenemos ganas de conocer a jóvenes españoles, pero tenemos miedo de que piensen que somos turistas, que sólo nos quedamos aquí unos días, y, que, luego, nos vamos y no volveremos jamás. Cuando salimos y llegamos a hablar con jóvenes españoles, lo primero que nos preguntan casi siempre es si somos turistas. Además, ellos tienen sus pandillas de amigos, y nosotros, las nuestras, $y$ tampoco queremos molestar.

Varios de los informantes subrayan que a veces no se lanzan a hablar en español porque se ponen nerviosos o que se inhiben porque tienen miedo de no encontrar las palabras adecuadas o cometer errores gramaticales:

Si me apetece o si me atrevo, hablo español. Depende un poco de la situación. Si me siento segura, me lanzo, pero a veces tengo miedo de decir algo de 


\section{Nordic Journal of Modern Language Methodology}

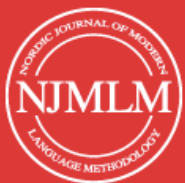

2019, 7 (2), 28-53 Peer reviewed

Temanummer: Spansk i Norge og det norske i den spansktalende verden.

forma errónea o de no entender nada cuando me hablan en español. Si al final me atrevo a hablar español, en una tienda, por ejemplo, y me entienden, me pongo muy contenta.

Me gustaría practicar el español más. En mi barrio casi todos los vecinos son de habla inglesa. Preferiría vivir en una zona de la ciudad donde viven familias españolas. [...] A veces resulta incómodo hablar en español. No me sale tan natural como quisiera. Para construir frases en español tengo que concentrarme mucho. Tal vez ponga demasiado enfoque en la gramática, y eso hace que me ponga más nerviosa todavía. Por otra parte, entiendo casi todo cuando alguien me habla en español.

En las entrevistas no se indagó sobre las causas relativas a estas sensaciones de incomodidad o ansiedad, pero se puede considerar que está relacionado con lo que se denomina foreign language anxiety (Horwitz 154), es decir, el aprendiz evita usar la lengua meta frente a situaciones específicas, entre otras cosas, porque tiene poca confianza en sus propias competencias. La timidez o ansiedad que experimentan estos informantes puede radicar en la percepción de las reglas sociales no expresadas explícitamente: la sensación de vivir en un gueto noruego en una comunidad española hace que sea difícil establecer relaciones con españoles. El que experimenten este aislamiento social coincide con los resultados del trabajo de Vartdal, quien destaca que es como si se trazara una frontera invisble entre la comunidad noruega y la española (Vartdal 50-54).

Desde el punto de vista de los informantes, una de las mayores ventajas de ir a un centro de enseñanza noruego en España es el bajo número de estudiantes por clase, lo cual facilita una enseñanza adaptada a su nivel y sus necesidades. Los informantes que empezaron con la asignatura de español en grunnskolen (la ESO) en Noruega, y que después se mudaron a España y siguieron con el español, expresan que en las clases de español en Noruega había muchos alumnos por clase, algo que dificultó el aprendizaje. El reducido tamaño de los grupos de español, posibilita que puedan practicar más la lengua en clase. Los que llevan muchos años en España destacan como positivo que recibieran clases de español una o dos horas semanales en la primaria, lo cual ha contribuido a afianzar sus conocimientos del español. Otra ventaja destacada por los informantes es la oportunidad que tienen de poner lo aprendido en las clases de español en práctica. Una de los 


\section{Nordic Journal of Modern Language Methodology}

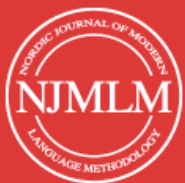

2019, 7 (2), 28-53 Peer reviewed

Temanummer: Spansk i Norge og det norske i den spansktalende verden.

entrevistados subraya que en las clases de español el tiempo es muy limitado y no pueden realizar tantas actividades orales como quisieran, dado que también hay que trabajar la gramática, la comprensión lectora, la expresión escrita, etc.:

En las clases de español aprendemos gramática, y eso es útil a la hora de saber cómo expresarnos correctamente en interacciones orales fuera de clase. En la escuela me gusta escribir textos en español, ya que escribiendo se tiene más tiempo para reflexionar sobre cómo expresarse y cómo construir el texto. Además, puede resultar divertido practicar el español oral fuera de la escuela.

A pesar de esta afirmación, varios de los informantes puntualizan que practicar el español en los contextos extraescolares requiere esfuerzo, y muchos de sus compañeros no están dispuestos a hacer este esfuerzo. Según ellos, si se usa el español o no en el tiempo libre, depende en gran medida de la actitud y la fuerza de voluntad de cada uno. Resumiendo, aunque existen oportunidades para la inmersión en español en el entorno físico inmediato, pocos las explotan.

\section{Planes para el futuro}

A casi todos los informantes les gustaría seguir desarrollando su competencia comunicativa en español después de terminar el bachillerato, no necesariamente estudiando el idioma a un nivel universitario, sino ampliando sus conocimientos prácticos del idioma, realizando viajes a otros países hispanos o simplemente siguiendo viviendo en España. Entre los informantes de $\mathrm{Vg} 3$, tres se plantean estudiar una carrera universitaria en España (estudios de veterinario, fotografía y e ingeniería biológica). Seis de los informantes de Vg3 tienen muy claro que volverán a Noruega para realizar sus estudios universitarios, aunque esto no quiere decir que deseen romper del todo los lazos con España. Una de los informantes se propone estudiar la carrera de turismo y liderazgo en Noruega, lo cual le permite hacer prácticas en España durante el tercer curso. Otro quiere estudiar para ser profesor de secundaria, así podrá dar clases de español, entre otras asignaturas. No obstante, entre los informantes que han decidido regresar a Noruega, tres indican que para ellos no es importante mantener los lazos con España, ni mejorar su español. Ninguno de los informantes planea estudiar una carrera de idiomas como 


\section{Nordic Journal of Modern Language Methodology}

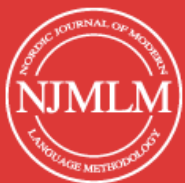

2019, 7 (2), 28-53 Peer reviewed

Temanummer: Spansk i Norge og det norske i den spansktalende verden.

filología española o traducción e interpretación, ni en Noruega ni en España u otro país hispanohablante, con la excepción de una estudiante de $\mathrm{Vg}$ 2, que se propone estudiar idiomas, cultura e historia en España, siendo estas sus asignaturas preferidas. Los informantes restantes, cuatro de $\mathrm{Vg} 2$ y dos de $\mathrm{Vg} 3$, no han decidido todavía qué carrera estudiar después del Bachillerato.

Las metas que se proponen respecto al español, coinciden en gran medida con las de los informantes residentes en Noruega: desarrollar sus habilidades lingüísticas a nivel oral coloquial. El gran interés que muestran por el español oral coloquial se puede deber a varios factores. Para la mayoría lo más importante a la hora de elegir la asignatura de español es poder usar el idioma en contextos informales. Además, debe también considerarse que también influyen las experiencias que han tenido con la lengua, y, quizás, no hayan alcanzado todavía el nivel suficiente para empezar a plantearse metas concretas de conseguir una amplia gama de registros en español. De todos modos, la adquisición de una competencia comunicativa básica y coloquial puede constituir una buena base para, en ocasiones futuras, empezar a desarrollar las destrezas y los distintos registros requeridos en ámbitos académicos y profesionales.

\section{Conclusiones y trabajos futuros}

En el presente artículo he presentado los resultados principales de dos estudios cualitativos sobre las oportunidades que tienen estudiantes de bachillerato noruegos de 17 y 18 años para practicar el español en contextos extraescolares, el primero realizado en Noruega en 2015-2016 y el segundo en España en 2016-2017.

Los resultados de estos estudios muestran que existe gran variedad en cuanto a cómo y en qué contextos los estudiantes explotan las oportunidades que encuentran en su vida diaria para interactuar en español. En líneas generales, todos los informantes, tanto los que residen en Noruega como los que residen en España, entran en contacto con el español por dos vías principales: 1) en el mundo físico en encuentros cara a cara, y 2) en el mundo virtual, a través de servicios de streaming (música, series de televisión, películas), y, en menor medida, a través de diarios y 
Temanummer: Spansk i Norge og det norske i den spansktalende verden.

revistas en línea, blogs y redes sociales. Su uso de la lengua en encuentros cara a cara presenta algunas características comunes: utilizan el español en el ámbito personal (conversaciones con familiares, amigos y/o conocidos, práctica de aficiones e intereses personales) y el ámbito público (situaciones de compra en tiendas, visitas a cafeterías, bares y restaurantes). Esto implica que sus prácticas discursivas tienden a ser orales y se restringen al empleo de un español coloquial.

Los informantes residentes en España tienen un mayor acceso al español en su entorno físico inmediato, pero no explotan siempre esta oportunidad. En general, y aunque hay excepciones, hay poco contacto entre los jóvenes noruegos y los jóvenes españoles. Los informantes residentes en Noruega tienen menos acceso al español en su entorno físico inmediato, pero son más conscientes de aprovechar cada ocasión que se le presenta para practicar la lengua. Acceden a páginas web y servicios de streaming en español, no solamente para entretenerse, sino también con el objetivo de informarse y mejorar sus destrezas receptivas (la comprensión auditiva y lectora). Así, su uso del español en los espacios digitales se convierte en una actividad intencionada.

Todos los entrevistados utilizan el español en una medida considerablemente menor que el inglés, tanto en encuentros cara a cara como en los espacios digitales y, al comunicarse en español, se sirven de sus conocimientos previos del inglés para asegurar la comprensión y para expresarse. Los resultados también muestran que tanto los factores externos como los factores internos al propio estudiante, como sus aspiraciones e intereses personales, desempeñan un papel importante en cuanto a su uso del español en ámbitos extraescolares. Los informantes muestran un particular interés por el aspecto comunicativo y social de la lengua, sobre todo la expresión oral, y casi todos creen que sus conocimientos prácticos del español les serán útiles en el futuro, en el ámbito personal y en el mundo académico y profesional, primordialmente para establecer redes de contacto.

Durante las últimas décadas, y sobre todo desde 2006, año en que entró en vigor el actual plan de estudios de lenguas extranjeras, en el aula de ELE, se ha destacado la relevancia de desarrollar actividades comunicativas que promuevan el uso de la lengua meta. El aprendizaje se inicia en el aula y se extiende a otros 
Temanummer: Spansk i Norge og det norske i den spansktalende verden.

contextos y a lo largo de la vida. Los informantes, aunque no aprovechan siempre las oportunidades que se les presentan fuera de la escuela para practicar el español, son conscientes de la importancia que tiene poner en práctica las competencias que han adquirido en el aula de ELE. Por consiguiente, es importante fomentar el desarrollo de las competencias comunicativas y las habilidades metacognitivas. Los docentes deben animar a los estudiantes a utilizar el español en contextos extraescolares y trabajar en el aula estrategías que les permitan poner en práctica los diferentes recursos lingüísticos que conocen para poder ampliar sus competencias en español por cuenta propia fuera del contexto del aula.

En posibles trabajos futuros que pueden desarrollarse a partir de los resultados de esta investigación, se debe ahondar en los diferentes factores, tanto externos como internos, que determinan el uso del español de los estudiantes en contextos extraescolares, y establecer recomendaciones didácticas dirigidas a fomentar este uso. También es necesario indagar más detalladamente en las conexiones que se establecen entre el aprendizaje formal e informal, los hábitos de lectura en español de los estudiantes en su tiempo libre, y de qué maneras se sirven del inglés como herramienta en la comunicación y el aprendizaje del español.

\section{Bibliografía}

Benson, Phil, and David Nunan. Learner Stories: Difference and diversity in language learning. Cambridge: Cambridge University Press, 2004. Impreso.

Christiansen, Ane and Berit Grønn. "Spansk nivå III - nye læringsmuligheter og deltakelse i læringsrom i hverdag og fritid." Nordic Journal of Modern Language

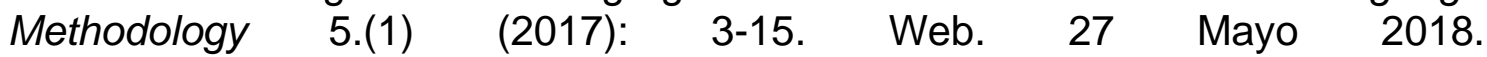
http://journal.uia.no/index.php/NJMLM/article/view/383\#.WwqP9iC-k2w

Fylkesmannen i Oslo og Akershus., n.p. Web. 15 Mayo 2018. https://www.fylkesmannen.no/Documents/Dokument\%20FMOA/Barnehager\%2 0og\%20oppl\%c3\%a6ring/Utdanning\%20i\%20utlandet/2017-

2018\%20Norske\%20skoler\%20i\%20utlandet\%20.pdf

Horwitz, Elaine K. "Foreign and second language anxiety." Language Teaching, 43. (2010): 154-167. Web. 27 Mayo 2018. doi:10.1017/S026144480999036 
Temanummer: Spansk i Norge og det norske i den spansktalende verden.

Instituto Cervantes. Marco Común Europeo de Referencia para las lenguas: aprendizaje, enseñanza, evaluación. (2002) Web. 27 Mayo 2018. https://cvc.cervantes.es/ensenanza/biblioteca_ele/marco/cvc_mer.pdf

Kozulin, Alex. "Vygotsky in Context". Vygotsky, L. Thought and Language [edited and translated by Hanfmann, Eugenia, Vakar, Gertrude, and Alex Cozulin]. Cambridge Massachusetts: The MIT Press, 2011. xxv-Ixxvii. Impreso.

Kreuger, Richard A., and Mary Ann Casey. Focus groups. A Practical Guide for Applied Research. United States of America: Sage Publications, 2015. Impreso.

Kunnskapsdepartementet [Norwegian Ministry of Education and Research], Læreplan for grunnskolen og videregående skole [Curriculum for elementary and secondary school]. Oslo: Kunnskapsdepartementet, 2006. Impreso.

Kvale, Steinar, and Svend Brinkmann. Det kvalitative forskningsintervju. Oslo: Gyldendal Akademisk, 2009. Impreso.

Lantolf, James P., and Steven L. Thorne. Sociocultural theory and the genesis of second language development. Oxford: Oxford University Press, 2006. Impreso.

Lantolf, James P., and Steven L. Thorne. "Sociocultural Theory and Second Language Learning." Theories in Second Language Acquisition. Ed. Bill VanPatten, and Jessica Williams. New York: Routledge, 2011. 201-24. Impreso.

Nasjonalt senter for engelsk og fremmedspråk i opplæringen (Fremmedspråksenteret), n.p. "Elevenes valg av fremmedspråk på videregående 2017-2018." Notat 3/2018. Web. 9 Junio 2018. https://www.fremmedspraksenteret.no/neted/services/file/?hash=d7cdadf58e4a 95528ad64680ceb6d8c3

Nasjonalt senter for fremmedspråk i opplæringen (Fremmedspråksenteret), n.p. "Elevenes valg av fremmedspråk på ungdomstrinnet. En analyse av utviklingen siden innføringen av Kunnskapsløftet." Notat 1/2015. Web. 9 Junio 2018. https://www.fremmedspraksenteret.no/neted/services/file/?hash=b1e85d2e8e29 fe4a73adcda8756d46ab

Skjær, Sonja. "Las destrezas orales en el plan de estudios de lenguas extranjeras en el sistema educativo escolar noruego." Red Electrónica de Didáctica del Español como Lengua Extranjera (redELE). (2009): 1-6. Web. 9 Junio 2018. http://www.mecd.gob.es/dam/jcr:987265f4-6807-461e-9becb51576ae243/2010-esp-0919skjaer-pdf.pdf

Säljö, Roger. Læring. En introduksjon til perspektiver og metaforer. Oslo: CappelenDamm Akademisk, 2016. Impreso. 


\section{Nordic Journal of Modern Language Methodology}

Temanummer: Spansk i Norge og det norske i den spansktalende verden.

Tornberg, Ulrika. Språkdidaktik. Malmö: Gleerups Utbilding, 2009. Impreso.

Utdannings- og forskningsdepartementet [Norwegian Ministry of Education and Research]. St. meld. nr. 30 (2003-2004). Kultur for læring. Oslo: Utdannings- og forskningsdepartementet, 2004. Impreso.

Utdanningsdirektoratet [The Norwegian Directorate for Education and Training], n.p."Subject curriculum for foreign languages (FSP1-01)". (2006): Web. 9 Junio 2018. https://www.udir.no/kI06/FSP1-01 ?lplang=http://data.udir.no/kl06/eng

Utdanningsdirektoratet [The Norwegian Directorate for Education and Training]. "Læreplan I fremmedspråk programfag i utdanningsprogram for studiespesialisering (PSP1-01)." [Foregin languages Programme Subject in Programmes for Specialization in General Studies] (2006): Web. 9 Junio 2018. https://www.udir.no/kI06/PSP1-01

Utdanningsdirektoratet [la Dirección Noruega para la Educación y la Formación]. "Utdanningsspeilet." (2015): Web. 92018. http://utdanningsspeilet.udir.no/2015/wpcontent/uploads/2015/06/Utdanningsspeilet_2015.pdf

Vartdal, Isabel Martha. "Et lukket paradis? En studie av hverdagen til norske ungdommer i Spania." Oslo: UiO. (2007): Web. 9 Junio 2018. https://www.duo.uio.no/handle/10852/15719

Vygotsky, Lev. Mind in Society: the Development of Higher Psychological processes. [edited by Cole, Michael and Sylvia Scribner]., Boston: Harvard University Press, 1978. Impreso.

Vygotsky, Lev, Thought and Language. [edited and translated by Hanfmann, Eugenia, Vakar, Gertrude, and Alex Cozulin]., Cambridge, Massachusetts: The MIT Press, 2012. Impreso. 